\title{
原子炉用黒鉛の破壊靭性に及ぼす切り欠き鋭さ 及び試験片寸法の影響
}

\author{
奥 達雄 - 石山新太郎 - 衛藤基邦 - 後藤泰 男 $*$ 浦島和 浩* · 稲垣道夫* \\ 日本原子力研究所東海研究所, $319-11$ 茨城県那珂郡東海村
$*$ 豊橋技術科学大学, 440 豊橋市天伯町

\section{Effects of Notch Sharpness and Size of Specimen on the Fracture Toughness of Nuclear Graphites}

\author{
Tatsuo OKU, Shintaro ISHIYAMA, Motokuni ETO, Yasuo GOTO*, \\ Kazuhiro URASHIMA* and Michio INAGAKI* \\ $\left(\begin{array}{c}\text { Japan Atomic Energy Research Institute, Tokai-mura, Naka-gun, Ibaraki } \quad 319-11 \\ \text { * Toyohashi University of Technology, Tempaku-cho, Toyohashi-shi } 440\end{array}\right.$
}

\begin{abstract}
The target of this research is to find the conditions for obtaining the valid fracture toughness value of nuclear graphite. The effects of the notch sharpness and size of specimen on the elastic-plastic fracture toughness values are examined. (1) The maximum notch root radius of curvature required for obtaining nearly constant fracture toughness values depends upon the kind of graphite, ca. $0.25 \mathrm{~mm}$ for the fine-grained isotropic graphite; IG-110 and ca. $1.2 \mathrm{~mm}$ for the coarse-grained near isotropic graphite, PGX. (2) The minimum specimen thickness for obtaining nearly constant fracture toughness values depends upon the kind of graphite, ca. $10 \mathrm{~mm}$ for $I G-110$ and ca. $20 \mathrm{~mm}$ for PGX. (3) The conditions that the specimen should satisfy for obtaining the valid fracture toughness values vary with the kind of graphite. (4) The linear elasticplastic fracture toughness is applicable to $I G-110$ graphite, and evaluation by the elastic-plastic fracture mechanics is not always necessary for $I G-110$, but it is considered that for PGX the correct fracture toughness values are not obtained unless the elastic-plastic fracture mechanics approach is applied.

[Received February 17, 1988; Accepted March 24, 1988]
\end{abstract}

Key-words : Nuclear graphite, Fracture toughness, Specimen size, Notch root radius of curvature, Validity

\section{1. 緒 言}

高温ガス冷却炬の炬心黒鉛構造物内の応力集中個所近 傍の潜在き裂の先端においては, 内部発生応力あるいは 外部応力の作用によりき裂が発生し, 進展する可能性が ある，黒鉛ブロック内の発生応力は原子炬が長時間運転 後停止したときに生じるので, その際特にき裂が進展す る可能性が大きい，黒鉛材料中のき裂の発生及び進展の 可能性を評価するには, 存在するき裂の形状と大きさ, 応力拡大係数又は $J$ 積分值及び破壊鞁性值に関する情 報を得ることが必要である。これまでいくつかの黒鉛に ついて線形弾性破壊力学が応用され, 破壊鞁性值が得ら れている(1) -4). しかしながら，有効な破壊鞀性值を得る ための諸条件についてはほとんど検討が行われていな い.

本研究の目標は，原子炉用黒鉛の有効な破壊䩲性值を 得るための条件を明確にすることである.ここでは，そ の条件の一つであると考えられる破壊靶性值に及ぼす切 欠鋭さと試験片寸法の影響を検討することを目的とし た。

\section{2. 実験方法}

供試材料は微粒等方性黒鉛 IG-110 及び粗粒準等方性 黒鉛 PGX である．素材ブロックと試験片の方向を図 1 のように定義した. 各方向の一般的機械的性質を表 1 に 示す. 試験片はコンパクトテンション型 (CT) で, そ の厚さが $20 \mathrm{~mm}$ のものを基準とし, 更にすべての寸法 が 2 倍及び 3 倍となるような試験片を製作した。 CT 基 準試験片の形状とサイズを図 2 に示す。厚さ $20 \mathrm{~mm}$ の 試験片については人工切り欠き部先端をカミソリ刃等に より切り欠き先端の曲率半径 $\rho$ が $0.015 \sim 2.5 \mathrm{~mm}$ とな るように加工した. 曲率半径の大きさは拡大投影器に よって測定した。 万能材料試験機を用いて試験片に $0.005 \mathrm{~mm} / \mathrm{min}$ のクロスヘッド速度で引張り荷重を加 え, そのとき試験片の切り欠き先端から進展して行くき 裂の長さを 50 倍のコンパレータを用いて測定した. 切 り欠きをはさむ試験片の両端に各 2 本の銅線を埋め込 み, それぞれ, 電流電圧端子とし, き裂の進展に伴う電 位差の変化を測定した。 き裂の進展量と電位差との関係 をあらかじめ求めておくことによって, 電位差の変化か らき裂の進展量を推定した. 電位差の変化率とき裂の進 


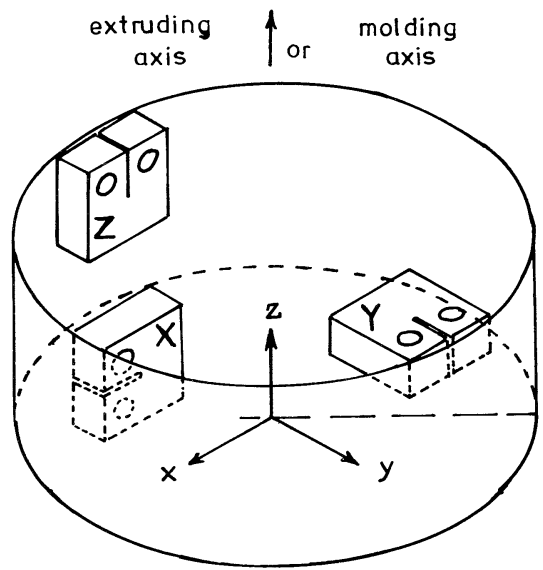

Fig. 1. Cutting scheme for CT specimens in the block.

Table 1. Mechanical properties of tested graphites.

\begin{tabular}{|c|c|c|c|c|}
\hline Property & \multicolumn{2}{|c|}{ IG-110 } & \multicolumn{2}{|c|}{ PGX } \\
\hline Direction & $\mathrm{z}$ & $x(y)$ & $\mathrm{z}$ & $x(y)$ \\
\hline $\begin{array}{l}\text { Apparent } \\
\text { Density } \\
\mathrm{g} / \mathrm{cm}^{3}\end{array}$ & & & & \\
\hline $\begin{array}{l}\text { Young's } \\
\text { Modulus } \\
\text { GPa }\end{array}$ & 9.61 & 10.2 & 6.65 & 8.12 \\
\hline $\begin{array}{l}\text { Poisson's } \\
\text { Ratio }\end{array}$ & 0.14 & 0.14 & 0.11 & 0.11 \\
\hline $\begin{array}{l}\text { Tensile } \\
\text { Strength } \\
\text { MPa }\end{array}$ & 24.9 & 24.0 & 7.87 & 7.19 \\
\hline $\begin{array}{l}\text { Compressive } \\
\text { Streng th } \\
\mathrm{MPa}\end{array}$ & 73.4 & 69.6 & 33.7 & 30.6 \\
\hline $\begin{array}{l}\text { Bending } \\
\text { Strength } \\
\text { MPa }\end{array}$ & 34.3 & 32.8 & 15.0 & 15.0 \\
\hline
\end{tabular}

展量との関係は図 3 に示すように IG-110 については 3 種類の厚さの試験片についてほぼ直線になることが分か る。また, PGXについても同様の結果が得られた。図 3 の中に PGX の場合の電位差の変化率とき裂の進展量 との関係を直線と式で示してある. 線形弾性破壊鞀性值 はASTM-E 399 に規定されている方法により，また， 弾塑性破壊靶性值はASTM-E 813 に規定されている方 法により評価した，ASTM-E 399 によれば応力拡大係 数 $K_{\mathrm{Q}}$ は次式によって与えられる.

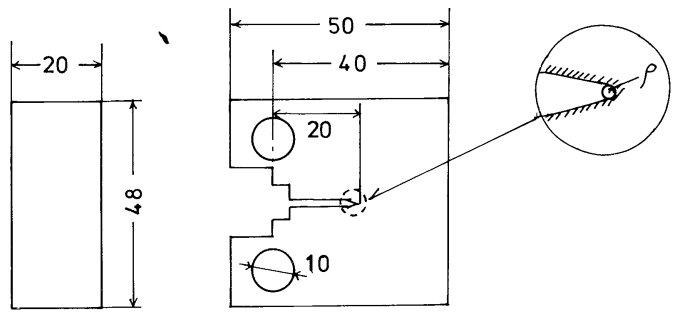

Fig. 2. Geometry of standard CT specimen.



Fig. 3. Relationship between increase in electrical potential and crack length.

$$
K_{\mathrm{Q}}=\frac{P_{\mathrm{Q}}}{B W^{1 / 2}} \cdot f(a / W)
$$

ここで,

$$
\begin{aligned}
f(a / W)= & (2+a / W)\left(0.886+4.64 a / W-13.32 a^{2} / W^{2}\right. \\
& \left.+14.72 a^{3} / W^{3}-5.6 a^{4} / W^{4}\right) /(1-a / W)^{3 / 2}
\end{aligned}
$$

$P_{\mathrm{Q}}$ は荷重-荷重線変位曲線における原点での接線の公配 の $95 \%$ 七カント線と曲線との交点に相当する荷重であ り，Bは試験片の厚さ，Wは試験片の幅である.また， ASTM-E 813 によればき裂進展開始に対応する $J$ 積分 值 $J_{\mathrm{i}}$ は次式によって与えられる.

$$
J_{\mathrm{i}}=\frac{A_{\mathrm{i}}}{B \cdot b} \cdot f\left(a_{0} / W\right)
$$

ここで,

$$
\begin{aligned}
& f\left(a_{0} / W\right)=2[(1+\alpha) /(1+\alpha)] \\
& \alpha=\left[\left(2 a_{0} / b\right) 2+2\left(2 a_{0} / b\right)+2\right] 1 / 2-\left[\left(2 a_{0} / b\right)+1\right] \\
& b=W-a_{0}
\end{aligned}
$$

$A_{\mathrm{i}}$ は $P_{\mathrm{i}}$ に対応する曲線下の面積であり， $a_{0}$ はき裂長 さである， $J_{\mathrm{i}}$ に対応する $K_{\mathrm{I}}$ 值は，次式によって評価し た。

$$
K_{\mathrm{I}}\left(J_{\mathrm{i}}\right)=\left[E J_{\mathrm{i}} /\left(1-\nu^{2}\right)\right]^{1 / 2}
$$

\section{3. 結果と考察}

\section{1 荷重-荷重線変位曲線}

$\mathrm{CT}$ 基準試験片（20 mm 厚さ）について切り欠き先端 曲線半径, $\rho$ が $0.015 \mathrm{~mm}$ の IG-110 黒鉛の場合の荷重- 
荷重線変位曲線の例を図 4 に示す。最大荷重より小さい 荷重でき裂が発生し，進展し始める．図中にある数本の 縦軸に平行な直線はき裂が進展したとき，き裂長さを測 定した点を示している．図には電位差法による結果も同 時に示してある．電位差が増加し始める点に対応する荷 重を $P_{\mathrm{iEP}}$ とし，この点をき裂進展開始点とみなした。 厚さ $60 \mathrm{~mm}$ の試験片でき裂先端の曲率半径が $0.1 \mathrm{~mm}$ の IG-110 と PGX 黒鉛について荷重-荷重線変位曲線を 図 5 に示す。この図でも電位差が増加し始める点に対応 する荷重及び最大荷重がそれぞれの黒鉛に対して示され

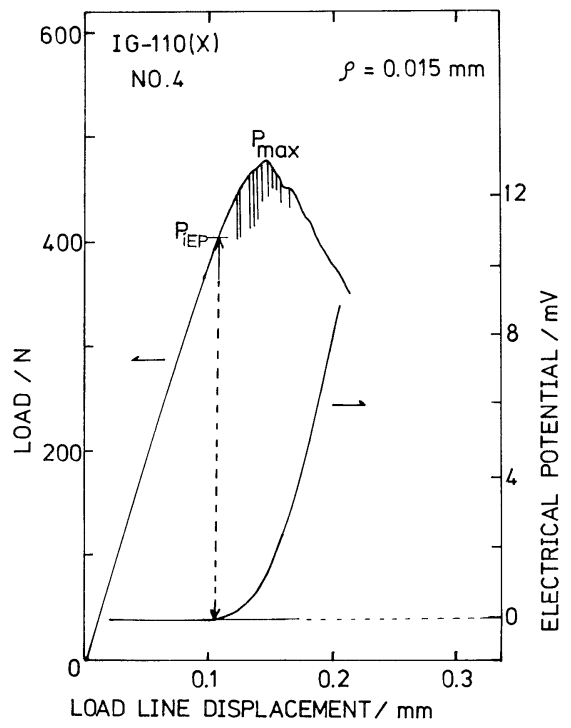

Fig. 4. Load-load line displacement curve for IG-110 standard CT standard specimen.

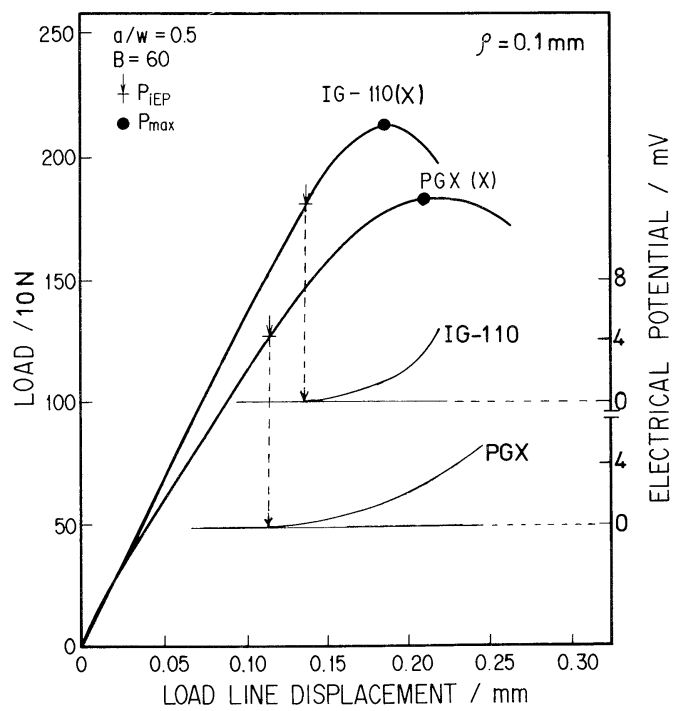

Fig. 5. Load-load line displacement curves for $I G-110$ and PGX graphites $(B=60 \mathrm{~mm})$.
ている. PGX 黒鉛の場合， IG-110 黒鉛の場合に比べて 最大荷重に対してかなり低い荷重でき裂の進展が始まっ ていることが分かる。

\section{2 破壊抵抗曲線 $(\boldsymbol{J}-\boldsymbol{R}$ 曲線）}

き裂進展に伴う $J$ 積分值の変化を調べると図 6 と図 7 が得られる. 図 6 は IG-110 黒鉛の例であり, $\rho=$ $0.25 \mathrm{~mm}$ の場合である.デー夕点を直線で近似したと き, その直線と縦軸との交点を $J_{\text {in }}$ によって定義すると,

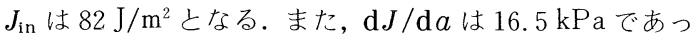
た。図7(a), (b) はPGX 黒鈶の例であり, $\rho=0.6 \mathrm{~mm}$ の場合である.これは IG-110 黒鉛の場合と異なること が分かる. PGX 黒鉛の場合まず異方性があり， $X$ 方向 の試験片が $Y$ 方向の試験片より $J_{\mathrm{in}}$ 值が小さいことが 特徵的である. 図 7 の例では $X$ 方向の $J_{\text {in }}$ 值が $59 \mathrm{~J} / \mathrm{m}^{2}$, $Y$ 方向の $J_{\text {in }}$ 值が $85 \mathrm{~J} / \mathrm{m}^{2}$ である。また, $\mathrm{d} J / \mathrm{d} a$ は両 者でほぼ等しく, $18.3 \mathrm{kPa}$ となった。また， $J_{\text {in }}$ 值は $P_{i \mathrm{EP}}$ に対応する $J_{\mathrm{iEP}}$ 值より若干大きい傾向がみられた。

\section{3 破壊靭性值}

$\mathrm{IG}-110$ ¿ PGX の両黒鉛について $K_{\mathrm{IQ}}, K_{\mathrm{Imax}}, K_{\mathrm{I}}(J)$ 及び $J_{\mathrm{IEP}}$ の值を表 2 に示す. IG-110 と PGX の $X$ 方向 については $K_{\mathrm{IQ}}$ と $K_{\mathrm{I}}(J)$ はほぼ等しい値を示している. PGX 黒鉛の場合 $K_{\mathrm{I} \max }$ に大きな相違はないにもかかわ らず， $J_{\mathrm{IEP}}$ は大きく異なっている．これは成形時の結晶 子の優先配向を反映しているものと考えられる，PGX 黒鉛の場合弾塑性破壊力学に基づく $J$ 積分値によって 破壊靯性值を評価しなければ正しい值は得られないと判 断される. 図 6 と図 7 加分かるように， $J_{\mathrm{in}}$ 值は曲線 を直線で近似しているので，真のき裂発生点に近いと思 われる $J_{\mathrm{iEP}}$ が $J_{\mathrm{in}}$ より小さいのは当然の結果である.

\section{$3.4 \boldsymbol{J}_{\mathrm{iEP}}$ 值に及ぼすき裂先端曲率半径の影響}

IG-110 と PGX 黒鉛について, 切り欠き先端曲率半 径に対する弾塑性破壊靱性値 $J_{\mathrm{iEP}}$ の変化を示したのが

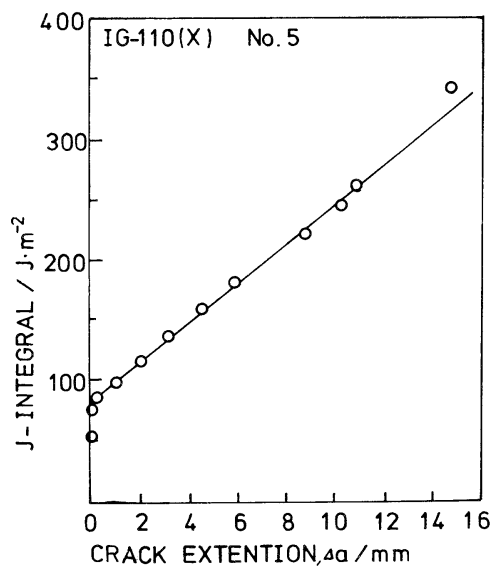

Fig. 6. Relation between $J$-integral and crack extention $(J-R$ curve) for IG-110 graphite. 
( a )



( b )

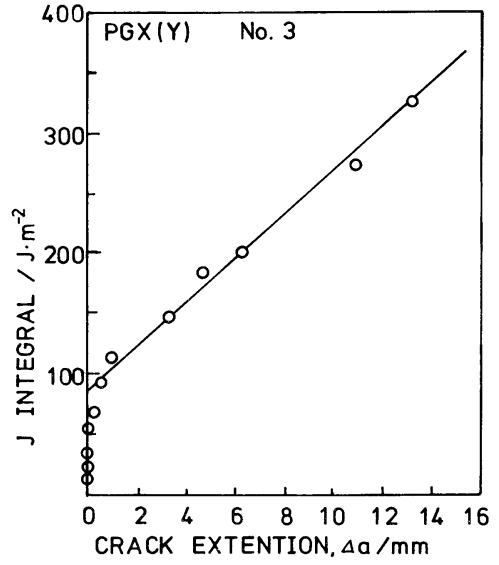

Fig. 7. $J-R$ curves for PGX graphite. (a) $\operatorname{PGX}(X)$, (b) $\operatorname{PGX}(Y)$.

図 8 である. IG-110 黒鉛では $\rho \leqq 0.25 \mathrm{~mm}$ で $J_{\mathrm{IEP}}$ はほ ぼ一定であり， $\rho \geqq 0.25 \mathrm{~mm}$ において $J_{\mathrm{iEP}}$ が大きく増加 しているのがみられる.これに対して, PGX 黒鉛では, $J_{\mathrm{iEP}}$ は $\rho \leqq 1.2 \mathrm{~mm}$ においてほぼ一定であり, $\rho \geqq 1.2$ $\mathrm{mm}$ でわずかに増加するにすぎない。これらの事実はそ れぞれの黒鉛におけるコークスフィラー粒子の大きさの 影響を反映しているものと考えられる.すなわちコーク スフィラー粒子の大きさは IG-110 黒鉛の場合 $20 \mu \mathrm{m}$, PGX 黒鉛の場合 $760 \mu \mathrm{m}$ とされているが， $\rho$ の值をフィ ラー粒子の大きさ以下にすればほぼ一定の破壊靶性值が 得られることが分かる。したがってこのことが有効な破 壊鞓性值を得るための一つの条件であるとみなすことが できる。

\section{$3.5 \boldsymbol{J}_{\mathrm{iEP}}$ 值に及ぼす試験片厚さの影響}

試験片の厚さを $5 \mathrm{~mm} \sim 60 \mathrm{~mm}$ まで変えて $J_{\mathrm{iEP}}$ 值を測 定した結果が図 9 である. IG-110 黒鉛では厚さ $10 \mathrm{~mm}$ 〜 $60 \mathrm{~mm}$ のとほぼ一定の $J_{\mathrm{iEP}}$ 值が得られるのに対し て厚さ $5 \mathrm{~mm}$ の場合わずかに小さい $J_{\mathrm{IEP}}$ 值となってい る. 一方, PGX 黒鉛の場合, 厚さ $20 \mathrm{~mm} \sim 60 \mathrm{~mm}$ では
Table 2. Fracture toughness values.

\begin{tabular}{|c|c|c|c|}
\hline \multirow[b]{2}{*}{ Specinen } & \multirow{2}{*}{$\frac{\mathrm{IG}-110}{\mathrm{X}}$} & \multicolumn{2}{|l|}{$\mathrm{PGX}$} \\
\hline & & $\mathrm{x}$ & $Y$ \\
\hline $\begin{array}{l}\mathrm{K}_{10} \\
\mathrm{MPa} \cdot \sqrt{\mathrm{a}}\end{array}$ & $\begin{array}{c}0.92 \pm 0.04 \\
\text { (5) }\end{array}$ & $\begin{array}{c}0.55 \pm 0.05 \\
\text { (4) }\end{array}$ & $\begin{array}{c}0.56 \pm 0.05 \\
\text { (5) }\end{array}$ \\
\hline $\mid \begin{array}{l}\mathrm{K}_{\mathrm{L}} \mathrm{nox} \\
\mathrm{MPa} \cdot \sqrt{\mathrm{n}}\end{array}$ & $\begin{array}{c}1.03 \pm 0.04 \\
\text { (5) }\end{array}$ & $\begin{array}{c}0.80 \pm 0.03 \\
\text { (4) }\end{array}$ & $\begin{array}{c}0.85 \pm 0.02 \\
\text { (5) }\end{array}$ \\
\hline $\begin{array}{l}\mathrm{K}_{\mathrm{I}}\left(\mathrm{J}_{\mathrm{i}} \mathrm{EP}\right) \\
\mathrm{MPa} \cdot \sqrt{\mathrm{a}}\end{array}$ & $\begin{array}{c}0.912 \pm 0.028 \\
\text { (3) }\end{array}$ & $\begin{array}{c}0.533 \pm 0.053 \\
\text { (3) }\end{array}$ & $\begin{array}{c}0.776 \pm 0.102 \\
\text { (5) }\end{array}$ \\
\hline $\mid \begin{array}{l}\mathrm{J}_{\mathrm{i}} \in \mathrm{P} \\
10^{-4} \mathrm{MPa} \cdot \mathrm{a}\end{array}$ & $\begin{array}{l}0.849 \pm 0.052 \\
\text { (3) }\end{array}$ & $\begin{array}{c}0.424 \pm 0.086 \\
\text { (3) }\end{array}$ & $\begin{array}{c}0.743 \pm 0.190 \\
\text { (5) }\end{array}$ \\
\hline$\rho$ & $\sim 0.25$ & $\sim 0$ & \\
\hline
\end{tabular}

$J_{\mathrm{IEP}}$ 值に大きな変化がないのに対して $5 \mathrm{~mm}$ 10 $\mathrm{mm}$ で は $J_{\mathrm{iEP}}$ 值が大きく低下している.これらの事実はき裂 の進展に伴うき裂前緑のプロセスゾーンの大きさが黒鉛 の種類によって異なることによるものと考えられるが， 詳細は明かでない。いずれにしても，IG-110 黒鉛では 厚さ $10 \mathrm{~mm}$ 以上, $\mathrm{PGX}$ 黒鉛では厚さ $20 \mathrm{~mm}$ 以上の試 験片を用いることが有効な破壊勒性值を得るための一つ の条件であるといえる.

\section{4. 結 論}

高温ガス炉用微粒等方性黒鉛 IG-110 と粗粒準等方性 黒鉛 PGX について, 弾塑性破壊勒性値に及ぼす試験片 切り欠き先端曲率半径の影響及び試験片厚さの影響をし



Fig. 8. Effect of notch root radius on $J$-integral, $J_{\text {iEP }}$ for IG-110 and PGX graphites. 


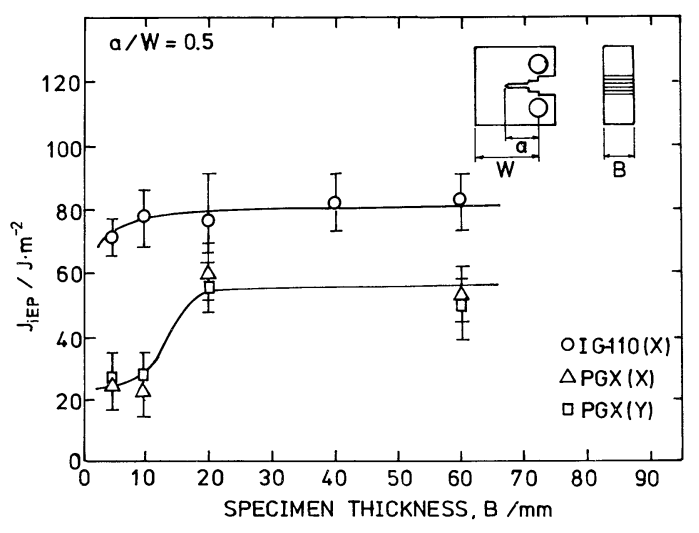

Fig. 9. Effect of specimen thickness on $J_{\mathrm{iEP}}$ for IG-110 and PGX graphites.

らべ，ほぼ一定の破壊勒性值が得られるための条件を検 討した。 その結果, 次の結論が得られた.

（1）ほぼ一定の破壊鞀性值を得るために必要な最大 の切り欠き先端曲率半径の大きさは黒鉛の種類に依存す る.すなわち, 微粒等方性の IG-110 黒鉛では約 0.25 $\mathrm{mm}$, 粗粒準等方性黒鉛 PGX では約 $1.2 \mathrm{~mm}$ となった。
また，粗粒黒鉛 PGX では切り欠き先端の曲率半径には 大きく依存しなかった。

（2）ほぼ一定の破壊鞀性值を得るために必要な最小 の試験片厚さもまた黒鉛の種類に依存する.すなわち, 最小試験片厚さは微粒等方性の IG-110 黒鉛では約 10 $\mathrm{mm}$, 粗粒準等方性黒鉛 PGX では約 $20 \mathrm{~mm}$ となった.

（3）上記の二つの結論により有効な破壊靶性值を得 るために試験片のみたすべき条件は黒鉛の種類によって 異なることが明かになった。

（4）微粒等方性黒鉛 IG-110 では, 線形弾性破壊力 学が適用できて, 必ずしも弾塑性破壊力学による評価は 必要ないと判断される. しかし, 粗粒準等方性黒鉛 PGX では, 弾塑性破壊力学による評価法を用いなけれ ば，正しい破壊靶性值は得られないと判断された。

\section{文献}

1) P. Marshall and E. K. Priddle, Carbon, 11, 541-46 (1973).

2) S.W. Freiman and J. J. Mecholsky, J. Mater. Sci., 13, 1249-60 (1978).

3) S. Sato, Y. Imamura, K. Kawamata, H. Awaji and T. Oku, Nucl. Eng. \& Design, 617 (1980).

4) F.H. Ho, R.E. Vollman and A.D. Cull, ASTM STP 791 (1982) pp. II-598-614. 